\title{
Colleagues Celebrate a Leader Who Empowered Others
}

\author{
Daniel Forbes (University of Minnesota) \\ James C Wetherbe (Texas Tech University)
}

KEYWORDS: Entrepreneurship, Management, Leadership, Learn From Leaders.

"If you want to lead, I would pay close attention to Dick's model....and if you are lucky enough to work for someone like this, you just won the lottery!" -- Brad Anderson

In honor of Dick Schulze's 80th birthday, we asked a few of his closest professional colleagues to share a few memories. We are proud to share their tributes here.

EIX Founding Editor Jim Wetherbe reached out to former Best Buy Chief Executive Officer Bradbury "Brad" H. Anderson and former Best Buy Vice Chairman Allen U. Lenzmeier. Anderson worked at Best Buy for more than 35 years, serving as CEO (2002-09) and president and chief operating officer (1991-2002). He also served on the Board from 1986 to 2010 . Lenzmeier joined the company in 1984 as chief financial officer and later served as treasurer, president of Best Buy Retail Stores, president and chief operating officer of Best Buy Co., Inc., and vice chairman. He retired in 2009 and is a member of the board of trustees for the Richard M. Schulze Family Foundation.

Current EIX Editor Daniel Forbes reached out to another former Best Buy executive, Joseph Pagano, who was senior vice president of enterprise entertainment and retired in 2006.

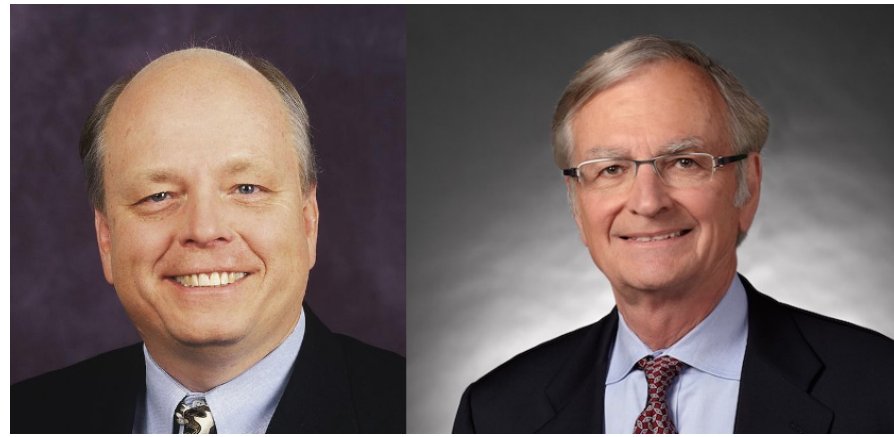

From left, former Best Buy senior executives and board members Brad Anderson and Al Lenzmeier

\section{Brad Anderson}

I learned so many things from Dick, but I would like to highlight two, which may sound so simple but are so rare.

I first worked with Dick directly at the end of 1979, when the company was in so much trouble we couldn't meet payroll. In my first meetings with Dick we talked about turning the company around, and Dick made promises about what he would do if we succeeded. My dad was a Lutheran pastor who had coached many people in circumstances similar to mine. He warned me to be careful, because had seen that promises like Dick's sometimes were quickly forgotten after the goal had been achieved. Despite this, I trusted Dick, and he was better than his word.

The second lesson relates to the first one. In planning the turnaround of the company, I found Dick believed we were not building a company that could survive, but one that would grow to 10 times the size we were then. At the time I thought he was crazy. We accomplished that in a few years, but when I came in for the victory lap, he denied he ever thought that was the objective. The objective he now remembered was 10 times the size we had just achieved! To get there, it was going to 
take every talent I had, along with the talents of all of us who worked there. This was true because Dick had the vision for what we would achieve but not how to achieve it: we had to fill in the blanks. This is great leadership, but it is so simple and counter-intuitive that I have found very few people who can or will lead in this fashion. If you want to lead, I would pay close attention to Dick's model....and if you are lucky enough to work for someone like this, you just won the lottery!

\section{Al Lenzmeier}

Dick was one of those unique entrepreneurs who was able to take a startup business and build it to become a multi-billion dollar, professionally operated business on an international scale. Dick's focus was always on the needs of the customer and on treating employees with a high degree of respect and integrity. Once you addressed these areas, profitability would follow.

"Dick's focus was always on the needs of the customer and on treating employees with a high degree of respect and integrity. Once you addressed these areas, profitability would follow." -- Al Lenzmeier

He was also a big risk taker and was always willing to innovate to stay ahead of the competition. He was also a very competitive person with a drive to be number one. At the same time, he was a good delegator and allowed people to make mistakes and stretch their ability to get the job done.

The unique culture that was built during his tenure has withstood the test of time.
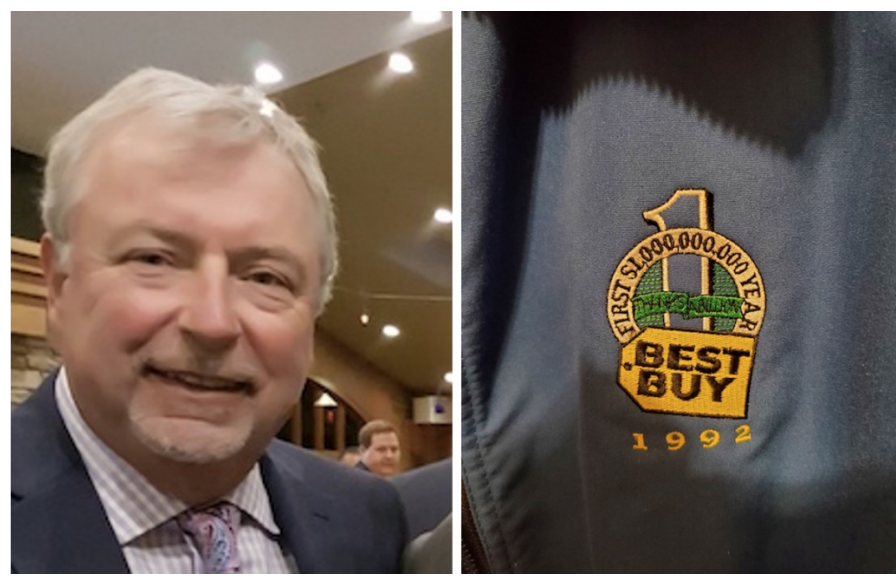

Joe Pagano, retired senior vice president, and the crest on his jacket commemorating Best Buy's first billion-dollar year.

\section{Joe Pagano}

The first time I saw Mr. Schulze was in 1992. At that time Best Buy was a regional player in a very competitive electronics industry. Dick quietly stepped into the weekly "All Marketing Meeting," which at the time included fewer than 50 people. On cue Dick began the short walk to the front of the room in his distinctive slow gait: part swagger and part stride. Even before he began speaking, I felt the force and energy of his persona. The room was quiet out of respect for our leader and anticipation of what he was about to say. His words assured the team that he knew where the industry was going, what Best Buy had to do to thrive in that evolving world, and that he was counting on everyone in that room to play a big part in our future success. The team had total trust and belief in him and his message.

Best Buy reached a billion dollars in annual sales for the first time in fiscal 1992. Mr. Schulze wanted everyone in the company to be recognized and share in the celebration. The company presented every employee, regardless of their rank or years of service, a first tier jacket in Best Buy blue with an embroidered crest. Mine still hangs in the closet today. The quality of jacket demonstrated Dick's attempt to do everything first class. The crest tells volumes more about the man: the number "1" speaks to his drive to finish at the top in any endeavor, the script "First $\$ 1,000,000,000$ Year" set expectations to start thinking about how the next billions in sales would be achieved. Finally, "Thanks a Billion" 
shared his great appreciation for our contributions.

In the mid-1990s a new campus site was selected in Eden Prairie. I drove to the site one Saturday morning. I was immediately struck that the sign identified our campus as "Best Buy, World Headquarters." We were not even a national player at that time, but Dick was telling us all that the vision was to be an international player and he was leading us there.

Happy Birthday, Dick. 